\title{
LA FUNCION FAMILIAR EN EL ACTUAL PLURALISMO RELIGIOSO: EL CASO DE LOS TESTIGOS CRISTIANOS DE JEHOVA
}

\section{M. ${ }^{a}$ DOLORES VARGAS LLOVERA}

Profesora del Area de Antropología. Universidad de Alicante

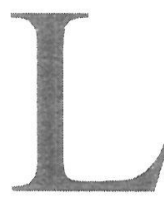

a familia constituye una institución universal. En todas las sociedades una parte importante del hombre transcurre dentro de la unidad social a la que llamamos familia, grupo doméstico o unidad familiar. Existen y han existido gran variedad de formas y tipos familiares con características muy distintas y pueden ser muchos los factores que determinen el tipo de familia al que un individuo pueda pertenecer.

En antropología la universalidad de la familia ha sido siempre aceptada y con más o menos discusiones teóricas se han marcado unos modelos para el estudio de la familia y el parentesco.

Se considera que el matrimonio, con todas sus variedades rituales y las formas reconocidas en cada sociedad, es el primer paso para el establecimiento de la familia. La definición clásica y tradicional, contempla al matrimonio como una unión legítima y estable de dos personas de distinto sexo que a partir de esta unión comparten residencia y economía, basada ésta sobre la división sexual del trabajo y teniendo como el objetivo más importante la legitimación de los hijos. Según Hoebel, «el nacimiento es la institución; la familia es el grupo cuyas acciones están dirigidas a alcanzar los fines de la institución» (1985:380).

La familia o el grupo doméstico parte de la vinculación de dos personas de distinto sexo por el matrimonio y de esta manera da comienzo la unidad familiar cuyas funciones, de acuerdo con la mayoría de los antropólogos, podemos enunciar de la siguiente manera: a) Establecimientos y canalización de las actividades sexuales proporcionando padres legales a los hijos. b) Crianza y enculturación de los jóvenes en una atmósfera de intimidad, preparándoles para aceptar los status que recibirán. c) La organización de la división complementaria del trabajo entre los esposos. d) Funciones educativas y establecimiento de relaciones de descendencia. De esta manera la familia es considerada como la más importante unidad social, es la unidad primaria de la sociedad y también de la cultura de los seres humanos. 
La primera unidad doméstica que se forma después de las distintas opciones de contrato matrimonial, es la que llamamos familia nuclear o conyugal-natal, que es la formada por un hombre y una mujer casados y sus hijos solteros. Fue G. P. Murdock (1949:I), quien confirmó, después de una primera hipótesis y basándose en el estudio del parentesco en culturas diferentes, que la familia nuclear es universal.

Esta definición de la familia nuclear es aceptada hoy generalmente dentro de las ciencias sociales. Pero tampoco debemos ser tajantes en creer que la familia nuclear está aislada de los otros lazos familiares, ya que no excluye la relación más amplia con su propia red familiar o la llamada familia extensa.

Las estructuras de los grupos familiares aceptados dentro del discurso antropológico no cierran las expectativas para que el estudio de las redes de parentesco, de cada cultura en general o grupo cultural en particular no configure una forma ideal de sistemas familiares que pueden o no ser aceptados por todos los individuos que la forman. Una cosa será, por lo tanto, el tipo de familia más valorado en una cultura o sociedad y otro los diferentes tipos que insistan dentro de ella por sus creencias religiosas, políticas o de cualquier otro orden. De esta manera unos grupos domésticos pueden basar sus estructuras familiares en el elemento económico y otros en el valor religioso, sin romper con las estructuras generales aceptadas por la mayoría de la sociedad. Así pues, es importante precisar que dentro de las estructuras familiares que cada sociedad establece, existe el modelo ideal que individualmente pone en práctica un grupo doméstico en concreto, no sólo el que la cultura de su sociedad define, sino el que por sus influencias recibe. En el caso que vamos a tratar, el modelo configurado por sus creencias religiosas. Por otra parte, creemos que quizás no debiera hablarse de la familia en general, sino más bien de tipos de familia; como dice Michel (1991:7) «son tan numerosos como regiones, clases sociales y los subgrupos existentes en el interior de la sociedad global».

La religión y la familia son dos principios interconectados en casi todas las culturas. La religión en general, y en nuestro caso en particular, sacraliza esencialmente los actos, las vivencias y las normas de la vida familiar, y que a partir de la aceptación de unos sistemas religiosos, facilitan a los individuos integrados en ellos las bases para construir la trama o parte de ella, de sus relaciones sociales; la familia que sigue unas normas religiosas, recibe su apoyo y las aportaciones fundamentales en su sistema de vida a través de sus creencias y si no las cumplen encontrarán las sanciones establecidas al no seguir las líneas de conducta marcadas por ei ideario religioso por ellos escogido.

El grupo social que estamos investigando no solamente tiene un interés religioso, sino que dentro de la visión holística que acompaña a las investigaciones antropológicas, nos lleva al estudio cultural de los 
Testigos Cristianos de Jehová, ya que en el seno de nuestra sociedad en general, y en particular en la comarca del Alto Vinalopó (Alicante) donde estamos trabajando, son un grupo numeroso a tener en cuenta; sus modelos de vida, basados en un principio religioso, nos darán a conocer cómo se desenvuelven socialmente, aportando a la sociedad donde están insertos, de mayoría católica, unas normas culturales que difieren de algún modo de las sancionadas por la mayoría.

La investigación que estamos realizando abarca todo el sistema cultural de los Testigos de Jehová, pero en este análisis vamos a centrarnos sólo en sus formas familiares, basadas en sus principios religiosos, que nos darán a conocer cómo son sus relaciones familiares y las normas que tienen que seguir según sus preceptos religiosos.

El cambio en las formas de las creencias y en la espiritualidad de sus miembros determina también cambios en los valores y en las prácticas familiares que influyen en todos sus aspectos: en la autoridad familiar, en la educación de los hijos, en el rol que protagoniza la mujer y en todo tipo de comportamientos familiares.

La metodología que hemos seguido para la recogida de datos ha sido la observación directa y la participación en los cultos, la lectura de sus libros y publicaciones referentes a la familia y las entrevistas personales. Todo ello nos lleva a seguir un esquema que va desde la forma y entendimiento del significado del matrimonio, pasando por los roles que ejercen el esposo, la esposa y los hijos, para finalmente centrarnos en la visión conjunta que tienen de la familia.

Son numerosos los libros, revistas y folletos editados por la sede central de los Testigos de Jehová, desde donde preparan a sus seguidores para llevar con rigor cristiano todos los momentos de su vida. Para que Dios los considere elegidos deben seguir las normas de vida que marca la Biblia, de acuerdo con su propia interpretación de ésta.

Analizando sus libros vemos que hablan de Cristo como la cabeza de la «Congregación de Dios» y que los miembros de ésta están sujetos a Jesús. Por ello, consideran el término «iglesia» o "congregación de Dios», como un grupo de cristianos. Hacen hincapié en que la «Congregación del Dios vivo» es un grupo particular de seguidores de Cristo y está compuesta por «todos los cristianos que hay en la tierra que tienen la esperanza de vivir en los cielos» ${ }^{1}$.

Si siguen las doctrinas establecidas por la organización, los seguidores de Cristo irán al cielo, tras ser sometidos a una prueba completa durante años de servicio cristiano. Siempre que consideren a Jehová «Dador de Vida y Proveedor», al mismo tiempo, El los dirigirá y dará leyes para que lleven una buena conducta.

Si no siguen estas leyes, entran en conflicto, ya que su obligación es obedecer a Dios. «Si amamos la vida y deseamos vivir para siempre

1 «Usted puede vivir para siempre en el Paraíso en la Tierra». Pág. 126. 
en la Tierra bajo la gobernación de Dios, debemos apresurarnos a adquirir conocimiento exacto de Dios, sus propósitos y sus requisitos» ${ }^{2}$. Los seguidores de las doctrinas de los Testigos de Jehová deben vivir bajo «el gobierno de Dios» y evitar todo tipo de prácticas y conductas inmorales. Para ellos son numerosas y variadas las pautas a seguir. No deben emborracharse, consumir tabaco o drogas, participar en fiestas desordenadas, tener costumbres egoístas y violentas, ser codiciosos, robar, tener egoísmo comercial y todo lo que signifique violencia y delitos contra las personas en general.

Dentro de las prácticas inmorales, resalta la importancia de evitar la inmoralidad sexual. Tienen que huir de todo tipo de fornicación, ya sea soltero/a o fuera del matrimonio, que lo consideran adulterio, y tienen prohibidos también la homosexualidad y el incesto. Aseguran que las leyes que Dios les ha dado para la protección de su felicidad obligan a que las personas no casadas no participen en relaciones sexuales. No deben tampoco leer libros, ni ver películas, ni programas de televisión que den énfasis a lo sexual, ya que lo que les puede suceder es una «agitación de los deseos sexuales; por eso deben evitar las actividades que agiten el apetito sexual». En uno de sus libros se lee: «no debería sorprendernos el que este mundo guiado por el diablo hiciera que pareciese normal y correcto tener relaciones sexuales con alguien con quien uno no estuviera casado. Pero si no hiciera eso, $i^{\mathrm{a}}$ quién estaría agradando?: A Satanás; no a Jehová. Para alegrar a Dios se tiene que huir de la fornicación» ${ }^{3}$.

Es muy importante para todos los miembros de la asociación el buscar amistades. Según sus normas deben acudir a la Biblia para saber qué personas deben escogerse, pues aseguran que afecta la relación con Jehová si se escogen mal. Están convencidos de que las malas compañías les acercan a Satanás y aconsejan «ser sabios al escogerlas escuchando el consejo de los ancianos de la Congregación» o según otra frase pronunciada en una conferencia pública, «evitar asociarnos con personas que nos perjudican» ${ }^{4}$.

La creación de la familia por parte de los Testigos de Jehová, pasa fundamentalmente por el rito del matrimonio religioso, según sus normas, y civil según establecen las leyes del país donde están ubicados.

Después del matrimonio civil, es cuando se dirigen al Salón del Reino con sus invitados para escuchar, en un acto religioso, una conferencia pronunciada por un anciano de la congregación. En ella que se les recuerda las responsabilidades bíblicas del uno para el otro, tal como señala en Efesios, 5:28-33:

2 «Usted puede vivir...». Op. cit., pág. 15.

3 «Usted puede vivir...». Op. cit., pág. 110.

4 Discurso público, día 12-1-1990. 
«De esta manera los esposos deben estar amando a las esposas como a sus propios cuerpos. El que ama a su esposa, a sí mismo se ama, 29 porque nadie jamás ha odiado a su propia carne; antes bien, la alimenta y la acaricia, como también el Cristo hace con la congregación, 30 porque somos miembros de su cuerpo. 31 «Por esta razón el hombre dejará a su padre y a su madre y se adherirá a su esposa y los dos llegarán a ser una sola carne.» 32 Este secreto sagrado es grande. Ahora bien, yo estoy hablando tocante a Cristo y a la congregación. 33 Sin embargo, también, que cada uno de ustedes individualmente ame a su esposa tal como se ama a sí mismo; por otra parte la esposa debe tener profundo respeto a su esposo.»

\section{Continúa en Efesios, 5:22-24:}

«22 Que las esposas estén en sujeción a sus esposos como el Señor, 23 porque el esposo es cabeza de su esposa como el Cristo también es cabeza de la congregación, siendo el salvador de este cuerpo. 24 De hecho, como la congregación está en sujeción al Cristo, así también lo estén las esposas a sus esposos en todo.»

Estos pasajes están tomados de la Traducción del Nuevo Mundo de las Santas Escrituras, versión de la Biblia, traducida, interpretada y publicada por la WATCHTOWER BIBLE AND TRACT SOCIETY OF NEW YORK, en Brooklyn, sede central de los Testigos Cristianos de Jehová en el mundo.

Además de este mensaje bíblico, son varios los consejos sobre la importancia del matrimonio desde el momento en que una pareja decide casarse. Según los Testigos y sus recomendaciones, «en el principio Jehová dijo la norma para el matrimonio cuando dio a Adán una sola esposa» ${ }^{5}$. Continúan diciendo que una de las principales razones por las que Jehová estableció el matrimonio fue por el compañerismo, para que dos personas cooperen juntas trabajando, para así edificar el matrimonio sobre una base fuerte y sólida como lo es Jehová, adquiriendo este compromiso o sentido de la obligación, ya que «ningún cónyuge debe exigir perfección al otro sino que cada uno debe comprender que el otro va a cometer errores, por lo tanto, ninguno de los dos debe esperar un matrimonio perfectamente feliz, puesto que es imposible que personas imperfectas como somos lo logren» ${ }^{6}$.

Antes de casarse, los Testigos insisten en que hay que llegar a conocerse a uno mismo para saber lo que pide al matrimonio; el hombre debe considerar seriamente si puede mantener a una esposa e hijos. El matrimonio debe significar el compromiso de compartir su vida y amarse mutuamente y será la devoción mutua al Creador lo que dará fortaleza a los enlaces matrimoniales, para que éstos duren toda la

\footnotetext{
5 «Usted puede vivir...». Op. cit., pág. 129.

6 «Cómo lograr felicidad en su vida familiar». Pág. 29.
} 
vida; por tanto, la elección del cónyuge no debe ser apresurada y deben estar consolidados en el amor y fomentar siempre los matrimonios dentro de los miembros pertenecientes a los Testigos de Jehová.

El adulterio es considerado una deshonra para el matrimonio, y no aceptan de ningún modo la poligamia, porque la Biblia les dice que tienen que ser fieles el uno al otro. El aborto no entra dentro de las normas de los Testigos de Jehová. Los hijos tienen que ser aceptados, ya que consideran que la «destrucción de vidas está en contra de la ley de Dios».

Una vez formado el matrimonio, el padre es el que se encarga de ejercer la jefatura en el sentido amplio de la palabra, ya que consideran que el «esposo es cabeza de su esposa como Cristo también es cabeza de la Congregación» ${ }^{7}$. De esta forma, cuando se casan, la responsabilidad corresponde al esposo; como cabeza de familia, él tiene el control en todos los asuntos. De la esposa dicen que está «en sujeción al esposo». La esposa debe ser buena ama de casa; «es una carrera que exige mucho de la persona y encierra diversas responsabilidades. Exige demostrar talentos de cocinera, decoradora, economista, madre y mucho más» ${ }^{8}$. Afirman que a la mujer le gusta trabajar bajo un techo de autoridad, con tal de que éste se ejerza apropiadamente. Continúan diciendo que la mujer está hecha para ser ayudante del hombre y complemento de él. Así pues, la mujer debe tener respeto al marido, no debe usurpar su jefatura, ha de ser responsable de los trabajos del hogar, no ser egoísta y complacer al esposo.

Considerando al esposo y esposa como una familia, ésta tiene que trabajar unida bajo la «gobernación del Reino de Dios» y aceptar que el padre ejerza la jefatura como lo manda Jehová Dios. La madre participa en la educación y disciplina de los hijos: «pero si la madre asume estos deberes a tal punto que el padre quede excluido, socaba la estructura de la familia. Lo bueno es bueno, pero una cosa buena puede hacerse mala si se lleva a un modo extremo» ${ }^{9}$.

Para que la familia siga las normas que dictan los Testigos, deben considerar la Palabra de Dios como realmente valiosa y esencial; además deben buscar espacios de tiempos regulares en los cuales toda la familia participe conjuntamente en la lectura y meditación de textos sagrados, con la ayuda de publicaciones que expliquen la Biblia. En ellas se considera al Creador, el originador del arreglo familiar, dando consejos prácticos a los matrimonios para que tengan éxito en su vida familiar, considerando que el arreglo de la familia que ha hecho Dios, es perfecto, pero puede desintegrarse si las instrucciones de Jehová se pasan por alto, de forma que los miembros de la familia no serán fe-

7 «Usted puede vivir...». Op. cit., pág. 239.

8 «Cómo lograr...». Op. cit., pág. 22.

9 «Cómo lograr...». Op cit., pág. 98. 
lices si no siguen las pautas bíblicas, y vaticinan que Jehová Dios, es la mejor autoridad sobre el matrimonio y la vida familiar.

La disciplina dentro de la familia es para todos los Testigos de Jehová muy importante, y consideran que no debe ser defectuosa, porque posiblemente esté relacionada con la violencia o la disposición criminal. De esta forma los padres tienen que emplear una acción disciplinaria para mejor interés de la vida de sus hijos y así ganarse el respeto de los mismos, contribuyendo a hacer un hogar pacífico, ya que ellos deben recibir las correcciones correspondientes. Consideran que los hijos necesitan ser educados en la disciplina, que los padres han de criarlos según las normas y la mentalidad de Jehová; ello será muestra de que los padres aman a sus hijos. Sin embargo, deben promover esta disciplina movidos por el amor, inculcarles que es necesario ser obedientes y respetar la autoridad, no deteriorando la comunicación mutua, y además comunicarles un código moral procedente de Dios, que puedan llevar más allá del círculo familiar.

Los hijos deben honrar a sus padres, mostrándose bondadosos y prestos para ayudar, siendo «respetuosos y amigables», $\mathrm{y}$ «al proceder así, al mismo tiempo honras a tu Creador» 10.

Como punto final de esta descripción sumaria del modelo de familia que preconizan los Testigos de Jehová, diremos que en la Biblia, tal como ellos la han traducido, encuentran todo lo necesario para seguir el camino que sus creencias les establecen: «En la Biblia Jehová Dios ha provisto instrucciones acerca de la vida familiar. Pero si estas instrucciones se pasan por alto, ¿qué sucede? Aunque el arreglo de la familia es perfecto puede desintegrarse. Entonces los miembros de la familia no son felices. Si se siguen las pautas bíblicas, de ello resulta una familia de éxito y feliz. Por lo tanto, es vital que entendamos precisamente cómo Dios hizo a los diferentes miembros de la familia y qué papeles se proponía que ellos desempeñaran» ${ }^{11}$. En otro lugar dice: «seguiremos cuidadosamente las instrucciones y la guía de Jehová Dios. Como resultado de ello Dios coronará nuestra dicha presente con el disfrute de vida eterna y felicidad abundante durante toda la eternidad que se extienda ante nosotros» ${ }^{12}$.

Cada grupo social, inmerso en una cultura determinada, puede configurar una forma ideal de modelo de vida. Las posiciones de los miembros que pertenecen a un grupo concreto, como son en nuestro estudio los Testigos Cristianos de Jehová, tanto en sus ideas y valores como en todo lo que concierne a la estructura familiar, pasan por la obligatoriedad de la aceptación de normas religiosas; es más, creemos que son una imposición de las mismas a todos los seguidores que han con-

10 «Cómo lograr...». Op cit., pág. 166.

${ }_{11}$ «Usted puede vivir...». Op. cit., pág. 238.

12 «Usted puede vivir...». Op. cit., pág. 249. 
seguido consagrarse a los ideales bíblicos que preconizan. Normas que individual y colectivamente creen que tienen que seguir porque son propias de su grupo ${ }^{13}$.

Tanto las creencias como las prácticas religiosas influyen poderosamente en las conductas sociales de los individuos, regulando y organizando sus vidas desde sus más íntimas vivencias hasta lo más pueril de la vida cotidiana, creando sus propias estructuras socioculturales dentro de la sociedad donde están instalados, y éste es el caso de los Testigos de Jehová.

La familia es el lugar en que, mediante la enculturación, la continuidad sociocultural, se transmiten los conceptos fundamentales que rigen la sociedad y ejercen múltiples influencias sobre otras instituciones y sobre el sistema social total.

En las sociedades actuales occidentalizadas, más tecnificadas e industrializadas, la familia sigue siendo una de las instituciones más importantes, a pesar de la aparición de numerosos cambios en los senos de las mismas. No es que el sistema familiar cambie con rapidez. Las estructuras familiares se mantienen a pesar del continuo proceso de cambio que en las últimas décadas se están produciendo en casi todas las instituciones tradicionales; quizás sea la familiar una de las más afectadas, ya que la tendencia actual en el interior familiar es la de una mayor libertad de los hijos con respecto a sus padres; asimismo la esposa ha obtenido una mayor autonomía respecto al trabajo y a la toma de decisiones familiares. Todo en conjunto ha ido transformándose hacia una mejor y equitativa convivencia familiar, desechando por parte de la familia occidental el rol que representaba la figura autoritaria del padre.

Las comunidades de los Testigos de Jehová, están formadas por un ideario religioso estricto, que les viene dado por la traducción de su Biblia, y la institución familiar no se escapa de este modelo religioso.

La vida familiar de los Testigos de Jehová es muy rigurosa respecto a las formas actuales de convivencia, sobre todo en el mundo urbano. No debemos olvidar que la mayoría de los actuales movimientos religiosos florecieron en un sistema de vida urbana y formando parte de la pluralidad de conceptos de vida que representa una ciudad. Y los Testigos de Jehová no son una excepción.

$\mathrm{Al}$ recopilar las formas de vida de los individuos pertenecientes a los Testigos de Jehová y más concretamente a la institución familiar,

13 Bott, E. Familia y red social. Madrid, 1990. Esta autora ofrece la siguiente explicación sobre el sentido de «normas sociales»: «en su sentido habitual el término «normas sociales» tiene una doble connotación. Significa normas que normalmente estén aceptadas en algún grupo o categorías de personas; pero también significa normas que los individuos creen que son propios de algún grupo o categoría». Pág. 241. Creemos que en ambos sentidos podemos aplicarlo al grupo religioso que estamos analizando. 
hallamos que sus esquemas de conducta parten del ideario que rigen sus normas religiosas; de esta manera nos encontramos, dentro de nuestra sociedad tradicionalmente católica y altamente secularizada, con una comunidad que preconiza y establece unas normas familiares altamente religiosas. Y esto no solamente en el ámbito familiar, ya que su dinámica religiosa tiene influencia entre sus amistades, en el trabajo o en cualquier otra relación social.

La unidad familiar entre los Testigos de Jehová es la conyugal o nuclear. Difícilmente encontramos un sistema de familia extensa. Sus normas religiosas promueven que para el buen funcionamiento familiar, sus componentes tienen que ser miembros de su organización. Deben contraer matrimonio con personas pertenecientes a la congregación, para el bien y la continuidad de sus creencias. Los matrimonios espiritualmente exogámicos debilitan o rompen la unión con sus creencias. Así podemos decir, que tienden a una exogamia biológica y a una endogamia religiosa y social. Esta norma no es exclusiva de este movimiento, ya que tanto en la actualidad como en el pasado, cualquier iglesia, secta o movimiento religioso, dentro de sus postulados, invitan prácticamente a manera de obligatoriedad al matrimonio endogámico espiritual, como una forma de aportar seguidores, en vez de disuadir a alguno. Este era y es un paso fundamental para la consolidación de su ideología religiosa, al mismo tiempo que social.

Con la creación de estos lazos familiares, a través del matrimonio, entre individuos que pertenezcan al grupo religioso, se proporcionan las bases para la ampliación y reestructuración de las relaciones familiares dentro de su ideario religioso.

Los Testigos de Jehová promueven modos o estilos de vida distintos a los que la actual sociedad secularizada ofrece. La vida familiar es estricta. En ella se mantiene una importante autoridad paterna y un claro dominio organizativo masculino. La autoridad del padre se extiende a la esposa, a sus hijos, pero siempre siguiendo las directrices que les establece la traducción de su Biblia y allí acuden para resolver los problemas que puedan surgir en la familia. En el libro sagrado esperan encontrar la solución y el consuelo de sus preocupaciones.

Para los Testigos de Jehová, sus creencias religiosas constituyen sus pautas de vida y las trasladan puntualmente a la comunidad donde están establecidos. Pueden parecernos esquemas sociales con cierto sabor anacrónico. Pero son conductas vivas, hechos culturales actuales en grupos determinados de individuos que pertenecen a nuestro entorno y son parte de nuestra sociedad.

\section{BIBLIOGRAFIA}

Bott, Elizabeth: Familia y red social. Ed. Taurus, Madrid, 1990.

Fromm, E. y otros: La familia. Ed. Península, Barcelona, 1986. 
González, A.; San Román, T. y Valdés, R.: Tres escritos introductorios al estudio del parentesco. Universidad Autónoma de Barcelona, Bellaterra, 1986.

Goody, Jack: La evolución de la familia y del matrimonio en Europa. Ed. Herder, Barcelona, 1986.

Hoebel, A y Weaver, Th.: Antropologia y experiencia humana. Ed. Omega, Barcelona, 1985.

König, René: La familia en nuestro tiempo. Ed. Siglo XXI, Madrid, 1981.

Lévi-Strauss, C.; Spiro, M. E., y Gough, K.: Polémica sobre el origen y la universalidad de la familia. Ed. Anagrama, Barcelona, 1974.

Michel, Andrée: Sociología de la familia y del matrimonio. Ed. Península, Barcelona, 1991.

Murdock, George P.: Social Structure. Ed. Macmillan, Nueva York, 1949.

Solimas, P.: «La familia». En: El Mediterráneo, los hombres y su herencia. Braudel, F. y Duby, G. Pág. 69-101. Ed. Fondo de Cultura Económica, México, 1989.

Swift, Artur L.: «Los valores religiosos». En: La familia. E. Fromm y otros. Pág. 107-122. Ed. Península, Barcelona, 1986.

Testigos de Jehová: Usted puede vivir para siempre en el paraíso de la tierra. Razonamientos a partir de las escrituras. Traducción del Nuevo Mundo de las Santas Escrituras. Cómo lograr felicidad en su vida familiar. La felicidad, cómo hallarla. Lo que los jóvenes preguntan. Revista Atalaya. Revista ¡Despertad! 